\title{
STUDY ON THE FORMATION OF SOMITES IN CHICK EMBRYO
}

\author{
NURUNNABI ASM ${ }^{1}$, PERVEN HA ${ }^{2}$, SHAHRIAH $\mathrm{S}^{3}$, RAYHAN KA ${ }^{4}$, BEGUM GN $^{5}$, BEGUM M$^{6}$, \\ HOSSAIN MM ${ }^{7}$
}

\begin{abstract}
:
Context: The chick embryo is used as a research model in developmental biology. The present study was designed to see the difference in the somite number evolution during the early embryogenesis in two hen breeds i.e. Local (deshi) hen and Plymouth Rock hen and to achieve a more profound knowledge of avian embryology as well as correlate with human early development.
\end{abstract}

Study design: Descriptive type of study.

Place and period of study: Histology and Embryology Laboratory, Department of Anatomy, Dhaka Medical College, Dhaka, from July to December 2004.

Materials \& Methods: The experiment was carried out on embryos groups at the age of 24, 36, 48, and 72 hours of incubation for two individual hen breeds. For each incubation period, 10 samples were prepared in the laboratory and studied in each breed. The number of somite was observed under the light microscope with low power objective and recorded for individual sample. Obtained data was statistically processed in order to quantify the influence of the genetic variation.

Results: The number of somite found in Local (deshi) hen and Plymouth Rock (broiler) hen after 24 hours of incubation were $1.02 \pm 0.34$ and $0.86 \pm 0.65$, after 36 hours $12.26 \pm 2.14$ and $10.24 \pm 2.58$, after 48 hours $21.34 \pm 2.57$ and $18.62 \pm 0.84$, after 60 hours $32.14 \pm 2.31$ and $29.82 \pm 2.72$ and after 72 hours $41.66 \pm 2.24$ and $39.89 \pm 2.95$ respectively.

Key words: Chick embryo, somite, early development, avian embryology.

J Dhaka Med Coll. 2010; 19(2) : 122-125.

\section{Introduction:}

Somitogenesis is the process of division of the anterior-posterior vertebrate embryonic axis into similar morphological units known as somites. These segments generate the prepattern which guides formation of the vertebrae, ribs and other associated features of the body trunk ${ }^{1}$. Somites develop from the paraxial mesoderm and constitute the segmental pattern of the body. They are formed in pairs by epithelialization, first at the cranial end of the paraxial mesoderm, proceeding caudally, while new mesenchyme cells enter the paraxial mesoderm as a consequence of gastrulation ${ }^{2}$. The rhythm of somite production is characteristic of the species at a given temperature. In the chick embryo, a pair of somite forms every 90 minutes at $37.8^{\circ} \mathrm{C}$ and a total of 52 somite pairs are formed during the somitogenesis process which lasts from day 1 to day 5 of development ${ }^{3}$. Ever since Aristotle discovered the chick embryo as the ideal object

1. Dr. Abu Sadat Mohammad Nurunnabi, Lecturer, Department of Anatomy, Dhaka Medical College, Dhaka.

2. Dr. Hosna Ara Perven, Senior Lecturer, Department of Anatomy, The Medical College for Women \& Hospital, Uttara, Dhaka.

3. Dr. Sunjida Shahriah, Assistant Professor, Department of Anatomy, Chattagram Maa-O-Shishu Hospital \& Medical College, Chittagong.

4. Dr. Khandaker Abu Rayhan, Associate Professor, Department of Anatomy, Prime Medical College, Rangpur.

5. Dr. Gul Newaz Begum, Associate Professor, Department of Anatomy, Anwer Khan Modern Medical College, Dhaka.

6. Dr. Mahamuda Begum, Associate Professor and Head, Department of Anatomy, Ad-din Women's Medical College, Dhaka.

7. Prof. Md. Motahar Hossain, Professor and Head, Department of Anatomy, Ibrahim Medical College, Dhaka. Correspondence: Dr. Abu Sadat Mohammad Nurunnabi, Lecturer, Department of Anatomy, Dhaka Medical College, Dhaka, Cell Phone: +8801712290608, Email: shekhor19@yahoo.com 
for embryological studies, the embryos have been described in terms of the length of time of incubation, and this arbitrary method is still in general use, except for the first three days of incubation during which more detailed characteristics such as the number of somites are applied. Many factors are responsible for the lack of correlation between chronological and structural age e.g. genetic differences in the rate of development of different breeds, seasonal differences in the viability and vigor of embryos, differences in the stage of development when incubation is started, differences in the quality of eggs, the lapse of time between laying and incubation, differences in the temperature of eggs when placed in the incubator, and in the size of individual eggs, differences in the temperature of incubation, and in type and size of the incubator etc. ${ }^{4}$. Local (deshi) hens are descendants of non-white Leg Horn hens, and are the main domestic poultry in our country. Plymouth Rock is a genetic improver breed, being the third in the world as importance and population number in the industrial aviculture $^{5}$. It is used almost exclusively as broiler hens. The present study was aimed to carry out the development patterns of the somite number and establish the standards of the somite number evolution during the early embryogenesis in two hen breeds and to achieve a more profound knowledge in avian embryology as well as correlate its similarities with human early development.

\section{Materials and Methods:}

A descriptive study was done in the Histology and Embryology Laboratory of Department of Anatomy, Dhaka Medical College, Dhaka, from July to December 2004 to see the difference in the somite number evolution during the early embryogenesis in two hen breeds i.e. Local (deshi) hen and Plymouth Rock hen. The fertilized eggs of the two breeds were collected from a poultry farm near Keraniganj upazilla, Dhaka.

\section{Preparation of embryo samples ${ }^{6}$ :}

Hens' eggs were incubated in a separate case for each breed for periods between 24 and 72 hours, so that the embryos were between stages 7 and 20 of Hamburger $\&$ Hamilton $(1951)^{4}$. The fertilized chicken eggs were incubated at $38^{\circ} \mathrm{C}$ and a relative humidity of $60 \%$ (Incubator model: Memmert UP 100, GmbH+Co., made in Schwabach, Germany). Each of the embryos was collected from the hatched egg and fixed in Carnoy's fluid for 3 minutes; then washed in $70 \%$ alcohol for 3-4 minutes and stained with Acid Carmine for 15-20 minutes. The next step was destaining with $70 \%$ alcohol for 2 minutes and dehydration with placing it into ascending grades of alcohol starting from $90 \%$ to $100 \%$ for about $10-20$ minutes. Then, it was cleared with xylene for 10 minutes. After that, the whole mount was made by removing the embryonic disc from the surface of the egg yolk and mounting it on a slide. The slides were examined under the light microscope with low power objective (Olympus CHB, made in Tokyo, Japan).

Counting the number of somites:

Shortly after the cephalic fold appears in the fore part of the primitive line in the chick embryo, cranial to the Hansen's node, and to one and other side of the neural canal, in the paraxial mesodermal band a splinter appears followed by another one placed ahead of the first one. This defines the first pair of somites, event that occurs usually from 20 to 25 hours of incubation ${ }^{7}$. The number of somites increase as embryo gets older. This is taking place by forming other pair of somites that will be placed inferior to the first ones. The abovedescribed process is named mesoderm segmentation. The measurements carried out during the early embryogenesis in the two hen breeds on embryos groups at the age of 24,36 , 48, 60 and 72 hours of incubation (Fig.1). Obtained data was statistically processed in order to quantify the influence of the genetic differences in the rate of development of different breeds.

The experiment was approved by the Departmental Committee for Care and Use of Animals.

\section{Results:}

The evolution of the somite number in the two groups correlating with the age of the embryos is presented in Table-I. 
Table-I

Evolution of the somite number in embryos from the two hen breeds

\begin{tabular}{lccccc}
\hline Name of breed & \multicolumn{5}{c}{$\begin{array}{c}\text { Number of somite in different age of } \\
\text { embryos }\end{array}$} \\
\cline { 2 - 6 } & 24 hours of incubation) & Mean \pm SD \\
\hline Local (deshi) hen & 36 hours & 48 hours & 60 hours & 72 hours \\
Plymouth Rock hen & $1.02 \pm 0.34$ & $12.26 \pm 2.14$ & $21.34 \pm 2.57$ & $32.14 \pm 2.31$ & $41.66 \pm 2.24$ \\
Difference & $0.86 \pm 0.65$ & $10.24 \pm 2.58$ & $18.62 \pm 0.84$ & $29.82 \pm 2.72$ & $39.89 \pm 2.95$ \\
\hline
\end{tabular}

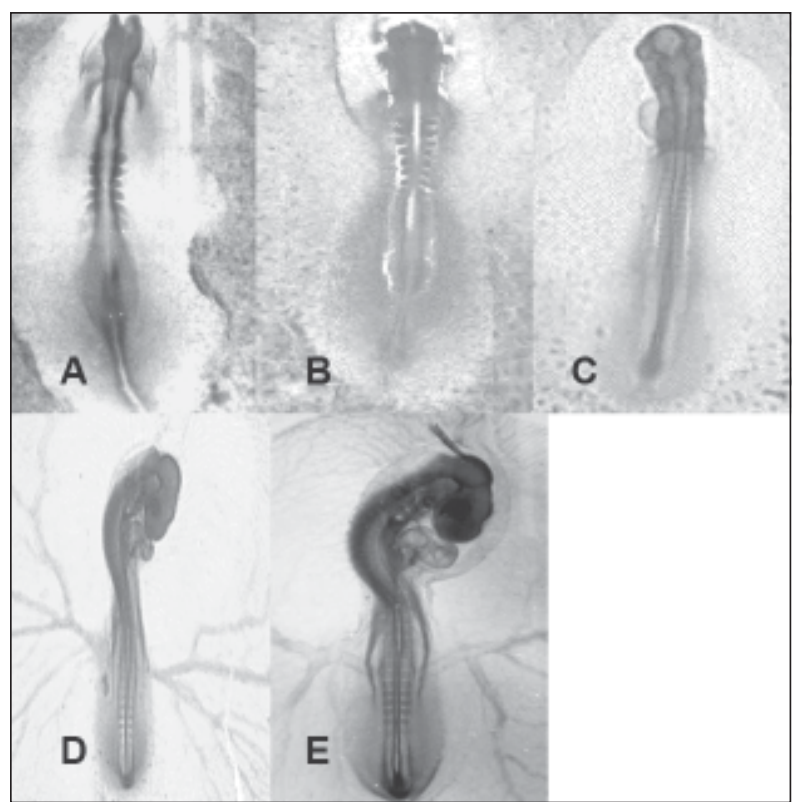

Fig.-1: Photomicrographs of the chick embryos at different incubation period: A. 24 hours, B. 36 hours, C. 48 hours, D. 60 hours, and E. 72 hours (Acid Carmine stain, $\times 50$ ).

\section{Discussion:}

The results of the present study show that the time evolution of the somite in the two embryo groups is carrying on using different models. It is observed that the mesoderm is increasing and segmenting in a different rhythm according to the embryos' age. During the first part of incubation (24-36 hours), the somite number that appears needs a longer time than after those embryos are going beyond the age of 36 hours of incubation. The literature says that the appearance of the first somite pair is accepted, if it takes place from 20 to 25 hours of incubation ${ }^{7}$. Studied embryos had, on average, 0.82 to 1.02 somites at the age of 24 hours. At 36 and 48 hours of incubation, the Local (deshi) breed embryos had +2.02 and +2.72 somites advantages respectively having an upward trend; then the difference slopped down to 2.32 and 1.77 at 60 and 72 hours of incubation respectively. The study suggests that the Plymouth Rock breed has got a slower evolution. Genetic differences in the rate of development of different breeds is very much contributing ${ }^{8}$ e.g. the embryo of the White Leghorn breed develops more rapidly than that of the Barred Plymouth Rock and hatches approximately a day earlier ${ }^{4}$. Moreover, some other factors are also important. It is admitted that both cell replication and differentiation engaged directly to the somite formation are conducted by the genetic structure of the individual ${ }^{9,10}$. Thereby, it explains the high individual variability of embryos regarding the appearance and accumulation of the somite number of the present study. It was also stated that each embryo develops with the vigor offered by its own aggregate genotype ${ }^{9}$. The differences in evolution of somites in two breeds may be the sum of differences in the quality of eggs, the lapse of time between laying and incubation, differences in the temperature of eggs when placed in the incubator, and in the size of individual eggs ${ }^{4,11}$.

Occasional failure in maintaining strict regulations about the above mentioned procedures was due to limitations of manpower and resources.

\section{Acknowledgement:}

We are grateful to Mr. Mirza Anwarul Haque, Laboratory Technologist, Histology and Embryology Laboratory, Department of Anatomy, Dhaka Medical College, Dhaka, for his sincere cooperation in preparation of the embryo samples.

(The study was a research project taken by the first six authors during their M.Phil. Part-I course, and the last author was the Professor \& Head, Department of Anatomy, Dhaka Medical College, Dhaka as well as the supervisor of the study, when it was done). 


\section{References:}

1. Baker RE, Schnell S, Maini PK. Mathematical models for somite formation. Current Topics in Dev Biol. 2008; 81: 183-203.

2. Christ B, Ordahl CP. Early stages of chick somite development. Anat Embryol. 1995; 191(5): 38196.

3. Pourquie $O$. The chick embryo: a leading model in somitogenesis studies. Mech Dev. 2004; 121(9): 1069-79.

4. Hamburger V, Hamilton HL. A series of normal stages in the development of the chick embryo. J Morphol. 1951; 88(1): 49-92.

5. Dronca D, Pacala N, Bencsik I, Lavinia S, Rodica $\mathrm{C}$, Oroian $\mathrm{T}$, et al. Somite number evolution during early embryogenesis in chicken embryos from Transylvanian Naked Neck and Plymouth
Rock breeds. Animal Breed Biotechnol.. 2008; 41(1): 73-7.

6. Harrison BM. Embryology of the chick and pig: a laboratory manual. $3^{\text {rd }}$ ed. Iowa: WM. C. Brown Company; 1956. p. 65-8.

7. Bellairs R. The development of somites in the chick embryo. J Embryol Exp Morph. 1963; 11(4): 697-714.

8. Daniel JC Jr. An embryological comparison of the domestic fowl and the red-winged blackbird. Auk. 1957; 74: 340-58.

9. Bellairs R. The segmentation of somites in the chick embryo. Boll Zool. 1980; 47: 245-52.

10. Fraser RC. Somite genesis in the chick. III. The role of induction. J Exp Zool. 1960; 145: 151-67.

11. Kendeigh SC. Factors affecting length of incubation. Auk. 1940; 57: 499-513. 